follows:-(1) It can be easily and quickly performed, provided the details I have suggested are observed. (2) It requires a very much smaller incision and less exposure of

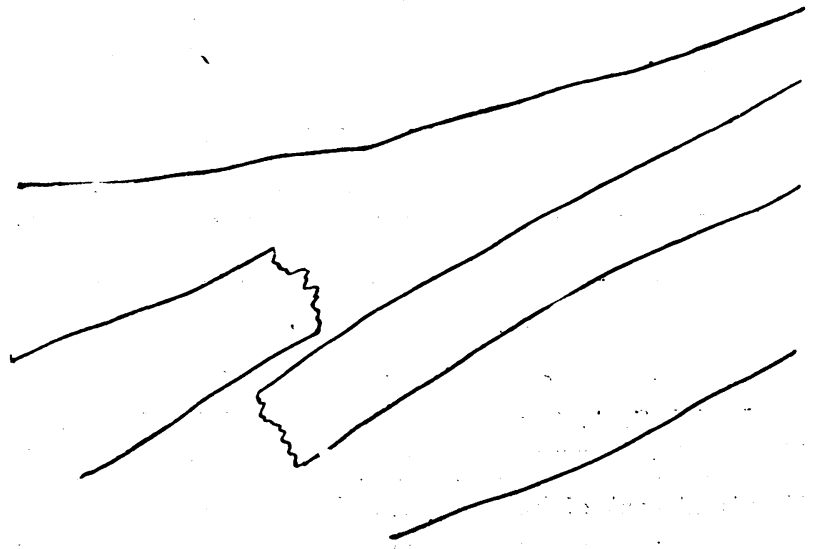

Fig. 8.-Fractured femur of a boy of 13, broken in its upprr third, with displacement of its upper fragment in front of the lower.
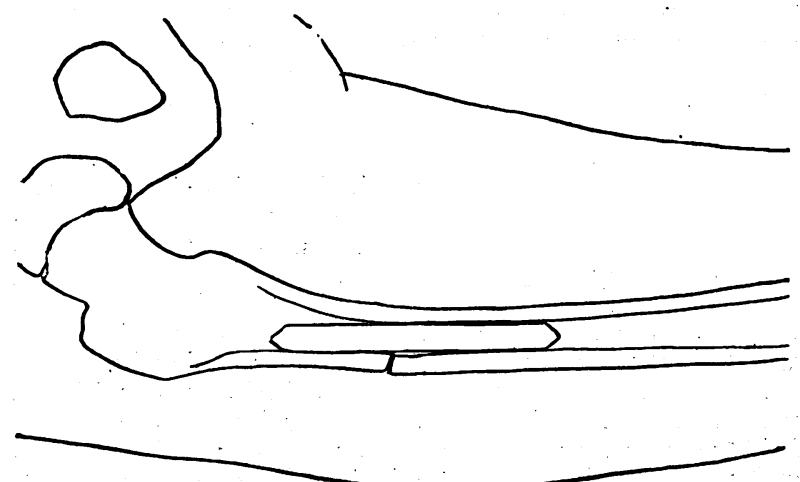

Fig. 9.-The same case shown in Fig. 8, a fortnight after the introduction of a bone peg.

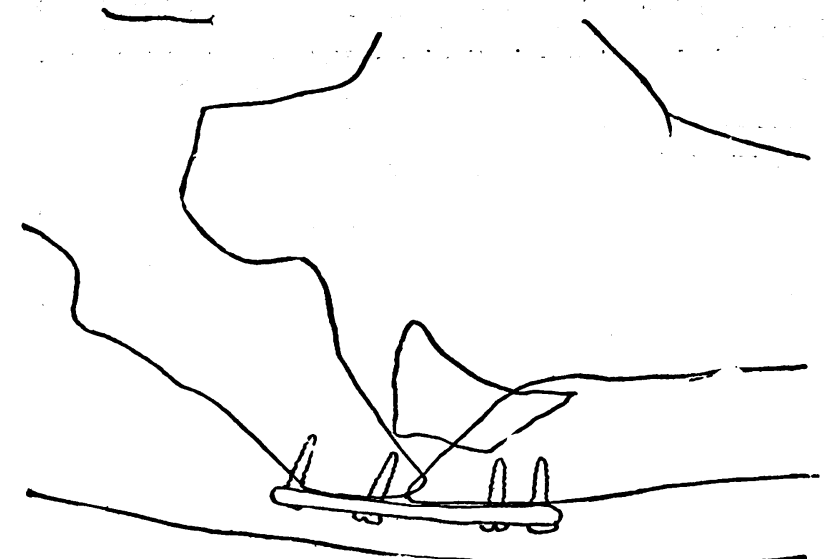

Fig. 10.-Femur of a man, broken in its uiper third, showing (o maintain the correct position of the bones.
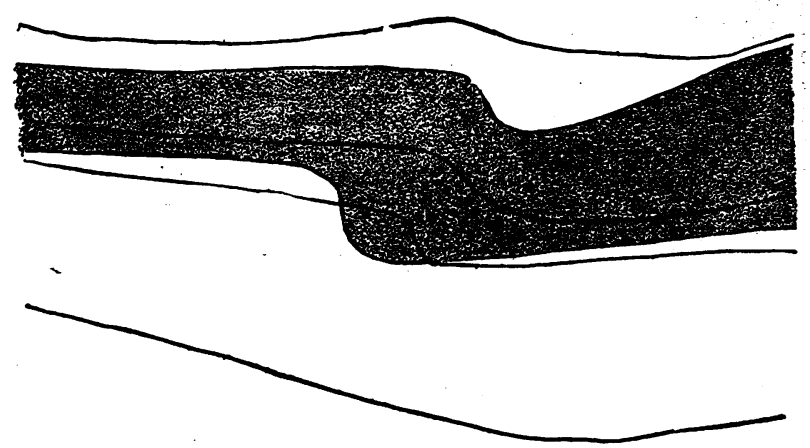

Fig. 11.-Malunited fracture of the leg bones eigh teen months after the accident. The tibia is shaded and the fibula only shown in outline. the soft parts. (3) It involves a minimum of injury to the periosteum. (4) It adjusts the broken bone in the correct position. (5) It allows slight movements betiveen

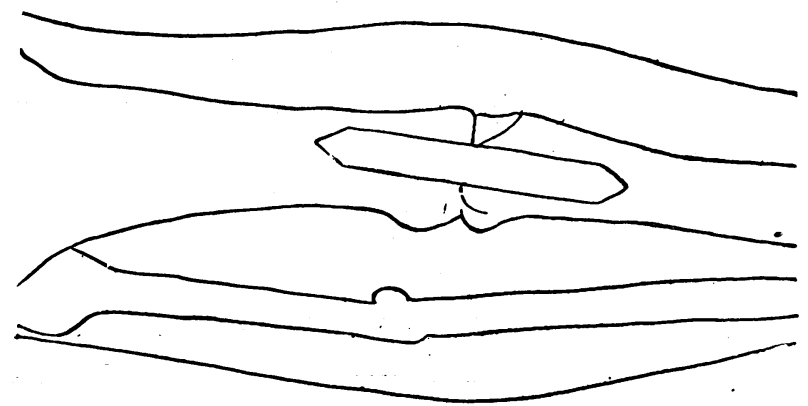

Fig. 12.-The same case as shown in Fig. 11, after the operation, showing the peg in position. A piece of the wire used to $\mathrm{r}$ raw the peg into position has been left to prevent the peg slipping up or

the fragments, which is beneficial for rapid union. (6) It makes the use of external splints unnecessary after the operation, and massage and movements are thus rendered possible as soon as the wound has healed.

[Figures 8, 9, 10, 11 and 12 are accurate outline dravings from the actual skiagrams, reproduced in this form for the sake of clearness. - ED.]

THE ACUTE AND SUBACUTE LESIONS

INDUCED IN THE SPINAL CORD BY INFECTION OF ITS LYMPH SYSTEM.

BY DAVID ORR, M.D.,

PATHOLOGIST, LANCASTER COUNTY ASYLUM, PRESTWICH,

$$
\text { AND }
$$

R. G. ROWS, M.D.

PATHOLOGIST, COUNTY ASYLUM, LANCASTER.

Tho research carried out during the past year has been a continuation of the investigations on the inflammatory phenomena induced in the central nervous system by infection of its lymphatic system. In our last paper we gave in detail the histological evidence which demonstrated that the path of the toxic lymph could be traced, by the presence of inflammatory roaction, along the infected sciatic nerve as far as the posterior root ganglion, and for a considerable distance along the spinal roots. The nerve had been infected by placing a celloidin capsule containing a broth culture of microorganisms in contact with it.

In our most recent experiments the spinal cord was infected in two ways-either by removing the laminæ of the vertebræ and suturing the capsule against the dura mater at the level of the lumbar enlargement, or by separating the muscles from the vertebræ in the dorsal region and placing a capsule against an intervertebral foramen.

All the experiments yielded positive results, but there were marked differences in the degree of the reaction, because in some cases the capsule had burst and a growth of organisms had occurred in the tissues and spread along the dura mater.

In the experiments in which the capsule had burst the changes in the spinal cord were of an acute nature. When there was no growth of organisms outside the capsule the reaction was sub-acutc.

Synopsis of the Phenomena in the Acute Series.

1. In the epidural tissue there were micro-organisms, polymorphonuclear leucocytes, and large lymphocytes.

2. Inflammatory reaction of the cells of the dura mater and pia mater, with the formation of polyblasts.

3. Within the spinal cord were found :-Proliferation of the adventitial and ondothelial cells, with the formation of polyblasts, and here and there of compound granular corpuscles; dilatation of the blood vessels, and the formation of thrombi within them; neuroglia proliferation; nerve cell degencration and neuronophagy.

Synopsis of the Phenomena in the Sub-acute, Series.

1. In the epidural tissue there were polymorphonuclear leucocytes, plasma cells, and polyblasts.

2. Plasma cells were present also in the dura mater and in the capsule of the posterior root ganglia; in the substance of the posterior root ganglia, and collected into a prominent group at the proximal pole; in the perineurium of the spinal roots and in the adventitial sheath of the vessels in it; in the 
pia mater and in the adventitial sheath of the vessels passing into the spinal cord.

3. Proliferation of the neuroglial cells.

A comparison of the phenomena of reaction in the two series of experiments shows that although they differ markedly in degree they have the same anatomical distribution.

In our last communication we drew a comparison between the sub-acute vascular lesions found in the infected sciatic nerves and those seen in the brains of general paralytics, and we assigned to both a similar mechanism of productioninfection of the lymph paths. The induction, in our last experiments, of acute lesions in the spinal cord which follow the anatomical distribution of the sub-acute series has widened the application of the research very considerably, and supports the most recent view that acute poliomyelitis is a lymphogenous infection.

\section{EIGHTIETH ANNUAL MEETING}

OF THE

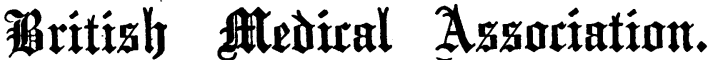

Held in Liverpool on July 19th, 20th, 22nd, 23rd, 24th, 25th, and 26th.

PROCEEDINGS OF SECTIONS.

\section{SECTION OF GYNAECOLOGY AND OBSTETRICS.}

Professor Henry Brig.gs, M.B., F.R.C.S., President.

PRESIDENT'S INTRODUCTORY REMARKS.

Professor Briggs, after extending a cordial welcome to members and visitors, continued: 'The prospect of three days' full employment on subjects of immense scientific and practical importance is consistent with the traditions of these annual gatherings of the Section and with the steady progress shown throughout the history of obstetrics and gynaecolcgy. Discouragements from any source or of any kind looming, or threatening to loom, in obstetrics must disappear under the combined influences of healthy mothers and children and an efficient obstetrical service. The latter requires the extension in populous centres of adequately equipped training schools in obstetrics for the medical student, the midwife, and the monthly nurse, A short statement of our local obstetrical history-in 1796 a ladies' charity, in 1841 a lying-in hospital, in 1869 an amalgamation of the two, at a date soon after the discoveries of anaesthetics and antiseptics - reveals an ancient institution which has outgrown its present, too small and always overcrowded, accommodation for 24 inpatients amidst an average of 2,000 out-patients yearly attended at their homes. On a central site, already acquired by the committee, a modern Maternity Hospital of 85 beds, by the great generosity of Sir William Hartley, is, at an early date, to be built. The endowment fund provided by other friends of the hospital has now reached the sum of $£ 15,000$; another $£ 5,000$ at least is desired. The gratifying assurance of this vigorous accession to the growth of our own local obstetrical training school will encourage the ever-increasing efforts of the hundreds of medical men and midwives in the district of Liverpool for the advancement of this branch of practice.

In addition to our membership of the British Medical Association and of our own purely local medical societies, we in this district, as obstetricians, are all members of the North of England Obstetrical and Gynaecological Society; its monthly meetings in one or other of the four university centres of Manchester, Liverpool, Leeds, and Sheffield, are well attended. To recall the society's origin in 1889 is to recite one of a long roll of varied and valuable public services, capably and courageously rendered by our neighbour, Sir William Sinclair, of Manchester, who has this year resigned his seat on the Central Midwives Board after ten years' faithful service. We know his enormous energy; we tecognize the gigantic debto obstetrics now owes to him.
The activity and the ability of the Royal Society of Medicine have amply compensated for the fusion of the London societies; the Obstetrical and Gynaecological Section has maintained its high level. With such organizations behind us we may be optimistic, and thus open the business of this meeting.

\section{DISCUSSION ON}

\section{THE RESULTS OF TREATMENT OF INFLAM-} MATORY DISFASE OF THE UTERINE

\section{APPENDAGES.}

\section{OPENING PAPERS.}

I.-W. S. A. GRIFFFITH, M.D.Camb., F.R.C.S.Eng.,

Physician Accoucheur, with charge of Out-patients, St. Bartholomew's Hospital.

THE treatment of inflammation of the ovaries and tubes has passed, since the time when many of us were students, from a simple treatment of symptoms; based on a very imperfect knowledge of the pathology of the disease, through a period of operative surgery which has since dominated treatment, and with the progress of antiseptic principles and operation technique has gradually achieved a high degree of success, to the great benefit and relief of many chronic and formerly incurable, as well as many of the acute cases.

During recent years advance in bacteriological research has enabled us to discover the causes of these inflammations, and with a more accurate knowledge of their pathological anatomy, their progress and termination, the medical treatment promises to prove of greater ralue than ever before, and to deprive the surgeon of some of the cases which would otherwise have come under his hands.

Medical treatment may now be said to begin with the means to prevent infection, not only by the use of dis. infectants, but by educating the public as to the sources and means of infection, the instruction of men suffering from gonorrhoea and gleet as to the suffering and misery produced by the communication of the infection after marriage, and the more thorough protection of women in labour.

Next in importance is the immediate arrest of infection of the vulva and vagina wherever this is possible, so as to prevent its extension to deeper tissues and organs, and at the same time placing the patient under the most favourable conditions for her recovery, by absolute rest, and attention to the common rules of medical practice, so that the various structures of the body may be enabled to fight their battle with the invading organisms with the best prospects of success, aiding them with such agents as serums and vaccines and such other methods as radiology and pharmacology provide for us from time to time.

It is of great interest to look back at the writings of those who were leaders in gynaecology in our student time, when the first investigations into the use of antiseptics were being made, and when the fear of opening the abdomen was only equalled by our ignorance of the condition inside it, and of the proper methods of treatment. If we look at the writings of such men as Matthews Duncan and Charles West in this country; Courty, Professor of Clinical Surgery at Montpellier; Scanzoni, Professor of Medicine at Wiurz burg, as representative of the best practice of their time in England, France, and Germany, we see that the treatment advocated by them was almost identical, and almost entirely medical; and that even in cases of pelvic abscess there was great hesitation in recommending any surgical treatment, with the result that large numbers of women were unrelieved and wandered from one doctor to another, or from one cure to another, unable to get the relief which modern surgery now affords.

It is interesting also to see how the advance of surgical treatment of the living led to, and was followed by a more exact knowledge of the anatomy and pathology of these diseases than was obtained from clinical observations and post-mortem examinations. The principles of treatment advocated at that time were common to all countries, and it may be of interest to see how far they are maintained at the present time. First in importance, then as now, were the commron-sense measures-Iying ir bed, attention to the 